\title{
Comparison of risk factors between colon cancer and rectum cancer in a single medical center hospital, Taiwan
}

\author{
Chao-Hsien Lee ${ }^{1}$, Peng-Lin Tseng ${ }^{2,3}$, Hong-Yi Tung ${ }^{1,4}$, Shu-Chen Cheng ${ }^{5}$, Ching-Yun Ching ${ }^{6}$, \\ Shih-Chang Chang ${ }^{7}$, Shu-Fen Wu ${ }^{6}$
}

\author{
${ }^{1}$ Department of Health Business Administration, Meiho University, Pingtung, Taiwan \\ ${ }^{2}$ Department of Nursing, Pingtung Christian Hospital, Pingtung, Taiwan \\ ${ }^{3}$ Department of Nursing, Meiho University, Pingtung, Taiwan \\ ${ }^{4}$ Department of General Surgery, Yuan's General Hospital, Kaohsiung, Taiwan \\ ${ }^{5}$ Department of Cancer Registry Division, Cathay General Hospital, Taipei, Taiwan \\ ${ }^{6}$ Department of Nursing, Yuan's General Hospital, Kaohsiung, Taiwan \\ ${ }^{7}$ Department of Colorectal Surgery, Division of Surgery, Cathay General Hospital, \\ Taipei, Taiwan
}

Submitted: 11 October 2016

Accepted: 12 September 2017

Arch Med Sci 2020; 16 (1): 102-111

DOI: https://doi.org/10.5114/aoms.2019.89407

Copyright $\odot 2019$ Termedia \& Banach

\begin{abstract}
Introduction: Colorectal cancer (CRC) is rapidly increasing in developed countries. In Taiwan, the incidence rate of CRC has increased during the past decade, but the 5 -year survival has remained at approximately $63 \%$. In this study, we sought to determine the 5 -year survival rate of patients diagnosed with colon and rectum cancer and to determine factors affecting survival. Material and methods: All patients from the Taiwan Cancer Database of the medical center hospital in North Taiwan between 2007 and 2013 were identified. Survival analysis was performed using Kaplan-Meier curves, and differences between the curves were analyzed using the log-rank test. Cox proportional hazards regression models were used to analyze survival by each variable.

Results: A total of 869 patients were included: 554 (63.8\%) patients had colon cancer and $315(36.2 \%)$ had rectum cancer. The mean survival time was $71.27 \pm 1.27$ months (colon group: $71.90 \pm 1.58$ months; rectum group: $67.88 \pm 1.95$ months). There was no significant difference $(p=0.493)$ between patients who had colon or rectum cancer. The forward stepwise Cox regression analysis results indicated that perineural invasion, distant metastasis, age, pathological differentiation grade, and obstruction were statistically significant for patients who had CRC, colon cancer or rectum cancer.

Conclusions: The long-term survival from CRC, colon cancer and rectum cancer remains promising, as $68.66 \%, 69.11 \%$ and $67.90 \%$ of patients are alive 5 years after being diagnosed, respectively. Perineural invasion was found to be an important factor related to the survival of patients who have CRC. Thus, early detection of CRC may help improve survival.
\end{abstract}

Key words: colorectal cancer, risk factors, survival, colon cancer, rectum cancer.

\section{Introduction}

Colorectal cancer (CRC) is the second and third most commonly diagnosed cancer type in females and males, respectively. The GLOBOCAN 2018 estimates for both sexes combined, the incidence and mortality rates

\author{
Corresponding author: \\ Shu-Fen Wu MSN \\ Department of Nursing \\ Yuan's General Hospital \\ 162 Cheng gong $1^{\text {st }} \mathrm{Rd}$ \\ 80249 Kaohsiung, Taiwan \\ Phone: 886-7-3351121 \\ E-mail: y355400@gmail.com
}


of 10.2 and 9.2 per 100,000, respectively [1-3]. There are slightly more incident cases and deaths among men than women in most parts of the world, except in the Caribbean [4]. In Taiwan, according to 2015 cancer registry data, the age-standardized incidence rates of CRC for males and females became 52.1 and 34.9 people per 100,000 population, respectively. The CRC mortality rate in 2017 was 24.7 per 100,000 population [5].

Cancer survival is an indicator of the overall effectiveness of health services in the management of patients. Studies showed that the 5-year survival rate of individuals with CRC was $65 \%$ in the United States. Early disease identification and treatment with newer agents would likely improve the survival of high-risk CRC patients; the 5-year survival rate of stage I and II CRC ranges from $80 \%$ to $90 \%$, whereas stage III and IV metastatic diseases are associated with 5-year survival rates of $60-71 \%$ and $8-13 \%$, respectively $[6,7]$. Currently, in Taiwan, the overall 5-year survival rate of CRC is $63.0 \%$ [8]. Fang et al. [9] found that the 5 -year survival rate was $74.3 \%$ for stage I CRC compared with $76.6 \%$ for stage II, $56.6 \%$ for stage III and only $16.7 \%$ for stage IV.

Colorectal cancer is considered primarily a "lifestyle" disease. The literature shows that demographic variables, such as age, gender, familial CRC history, diets high in calories and animal fat, alcohol consumption, and obesity, in addition to other factors, such as tumor site, size, grade, histologic type, TNM stage, and carcinoembryonic antigen (CEA) level, have all been found to significantly affect survival in CRC [3, 10-13]. In the present study, we used population-based data from the Taiwan Cancer Database of the medical center hospital in North Taiwan to compare socio-demographic and clinic-pathological characteristics, prognostic factors, and overall survival between 2 groups of CRC patients, i.e., those with the colon or rectum as the primary site.

Chewing betel nuts in Taiwan is a unique characteristic of this culture. Previous studies have demonstrated that retaining and subsequently swallowing betel quid juice and unripened betel fruit in the quid both increase the risks of contracting oral cancer [14]. Because swallowing betel nut juice will affect the gastrointestinal tract, we added chewing betel nuts as a factor in demographic variables to explore whether it affects survival of CRC patients. This study aimed to explore the survival rate and the potential factors influencing survival among CRC, colon cancer and rectum cancer patients in northern Taiwan. The research questions involved were as follows:

1. What is the 5 -year survival rate of colon cancer and rectum cancer in this area?
2. Does smoking, drinking, or chewing betel nuts affect survival in this population?

3. What are the risk factors affecting the survival of CRC, colon cancer and rectum cancer?

\section{Material and methods}

\section{Study population}

In this study, we conducted a single-center, retrospective cohort study to estimate the survival outcome of patients diagnosed with colorectal carcinoma at Cathay General Hospital in North Taiwan between 2007 and 2013. Data were extracted from medical records and the cancer database by trained data collectors. The eligibility criteria included the following: diagnosis and treatment of CRC; the International Classification of Disease for Oncology, $3^{\text {rd }}$ edition (ICD-O-3) topographical codes of C18.0-C20.9 (excluding C18.1) and morphology codes of 8000-8152, 8154-8231, 8243-8245, 8247-8248, 8250-8576, 8940-8950 and 8980-8981. Participants who showed more than one type of cancer, ICD-O-3 morphology codes of 8935-8936, 8153,8240-8242,8013,8246, 8249 and $9590-9720, a T_{x} N_{x} M_{x}$ stage of 888 or 999 , BBB case, or a survival time of less than six months were excluded. Demographic data extracted included gender, age at diagnosis, body mass index (BMI), smoking history, betel nut chewing status, drinking habits, and date of last contact or death. The evaluated tumor characteristics included primary site, histologic type, grade/differentiation, and size, as well as treatment type and regional lymph node or distant organ metastasis. The disease staging was based on the American Joint Committee on Cancer (AJCC) criteria; cancer site-specific factors included CEA, circumferential resection margin (CRM), tumor regression grade, perineural invasion, obstruction and perforation. Survival data were obtained using death and date of last contact records to determine the current situation or date of death of each patient.

\section{Ethics}

The study was reviewed and approved by the hospital's institutional review board (No. CGHP104060).

\section{Statistical analysis}

Statistical analyses were performed using SPSS software (version 22.0 of SPSS). Survival time was calculated as the time from diagnosis to the censoring date or the date of death. Continuous variables are described by summary statistics, such as the mean, standard deviation (SD) and percentage (\%). The data were also analyzed using Kaplan-Meier curves, and differences between 
the curves were analyzed by the log-rank test. Cox proportional hazards regression models were used to analyze survival by each variable.

\section{Results}

\section{Sample characteristics}

A summary of the demographic and clinical characteristics of the participants is presented in Table I. The follow-up period continued to December 2015. We retrospectively evaluated 869 patients from 2007 to 2013. The majority of the patients were male, and the median age at diagnosis was 64 years (range: 17-97). Approximately $43.04 \%$ of the patients had normal BMI values $\left(18.5-24 \mathrm{~kg} / \mathrm{m}^{2}\right)$, while $386(44.42 \%)$ were either overweight or obese $\left(\mathrm{BMI} \geq 24 \mathrm{~kg} / \mathrm{m}^{2}\right)$. Only $14.4 \%, 18.04 \%$, and $3.45 \%$ of patients had a drinking, smoking and eating/chewing betel nut history, respectively. We found that 554 (63.75\%) patients were diagnosed with cancer of the colon. The most common histopathology type reported was adenocarcinoma (91.71\%), and 34.87\% (colon: $32.49 \%$; rectum: $39.05 \%$ ) of patients had stage III disease at the time of diagnosis, while $27.39 \%$ had stage II (colon: $30.14 \%$; rectum: $22.54 \%$ ). Regional lymph node involvement and distant metastasis were found in $45.22 \%$ and $14.04 \%$ of patients, respectively. More than $50 \%$ of patients had no obstruction at presentation. Only $5.45 \%$ of patients had postoperative CRM.

\section{Survival outcome}

The mean survival time was $71.27 \pm 1.27$ months (colon group $71.90 \pm 1.58$ months; rectum group $67.88 \pm 1.95$ months) (Table II). The 5-year survival rates for $\mathrm{CRC}$, colon cancer and rectum cancer were $68.66 \%, 69.11 \%$ and $67.90 \%$, respectively. There was no significant difference $(p=$ 0.493 ) between patients who had colon or rectum cancer (Figure 1). The 5 -year survival rates for CRC patients who had stage I, II, III or IV cancer were $91.20 \%, 82.20 \%, 63.20 \%$ and $21.70 \%$, respectively (Figure 2). The 5-year survival rate of colon cancer at stage I, II, III and IV was $94.40 \%, 82.30 \%$, $65.00 \%$ and $22.60 \%$, respectively. In the rectum group, the rates were $87.00 \%, 82.10 \%, 60.80 \%$ and $22.90 \%$, respectively. Log rank tests showed that cancer stage was associated significantly with survival rate $(p<0.001)$.

From the univariate Cox regression model, factors considered effective for CRC 5-year survival were age at diagnosis, tumor status, regional lymph node metastasis, distant organ metastasis, cancer stage, pathological differentiation, perineural invasion, tumor size, KRAS mutation, CRM, obstruction, and perforation (all $p<0.05$ ). Site-specific analyses of colon and rectum cancer for confounders were also performed. However, there were no significant differences in perforation, CEA, and BMI or smoking, drinking, and betel nut chewing behavior for the two groups. Details are shown in Table III.

As shown in Table IV, the risk of CRC death was high among patients with age $\geq 65$ years $(H R=2.36$, 95\% Cl: 1.76-3.17); high grade of pathological differentiation ( $\mathrm{HR}=1.84,95 \% \mathrm{Cl}$ : 1.27-2.66); perineural nerve invasion ( $\mathrm{HR}=2.90,95 \% \mathrm{Cl}: 2.03-4.14)$; metastasis to distant organs $(\mathrm{HR}=2.78,95 \% \mathrm{Cl}$ : 2.00-3.87); intestinal obstruction $(H R=1.38$, 95\% Cl: 1.04-1.84); and regional lymph node metastasis ( $\mathrm{HR}=1.81,95 \% \mathrm{Cl}: 0.28-2.57)$. The risk of colon and rectum cancer deaths for patients aged $\geq 65$ years was 2.87 (95\% Cl: $1.91-4.30)$ and $2.39(95 \% \mathrm{Cl}$ : 1.49-3.83); that of high grade of pathological differentiation was 1.73 (95\% Cl: $1.09-2.75)$ and 2.59 (95\% Cl: $1.27-5.29)$; that of perineural invasion was $2.60(95 \% \mathrm{Cl}: 1.62-4.10)$ and $4.16(95 \% \mathrm{Cl}$ : 2.29-7.57); and that of metastasis to distant organs was $3.21(95 \% \mathrm{Cl}$ : 2.09-4.92) and 2.48 (95\% Cl: 1.39-4.42). Regional lymph node metastasis was only found to be significant in the colon cancer group ( $\mathrm{HR}=1.86,95 \% \mathrm{Cl}: 1.44-2.39)$. A tumor size $\geq 50 \mathrm{~mm}(\mathrm{HR}=1.65,95 \% \mathrm{Cl}: 1.03-2.63)$ significantly predicted rectum cancer death.

\section{Discussion}

This study observed factors connected with disease survival in a population-wide cohort with access to universal healthcare, with a specific focus on recognizing the 5-year survival rate and risk factors of CRC, colon cancer, and rectum cancer. In the present study, the 1, 3, and 5-year relative survival rates of CRC were better than those in Malaysia and other countries, such as Singapore, Korea, Iran, and India $[15,16]$. In the present study, the 5 -year survival rate was $68.66 \%$ in CRC patients, $69.11 \%$ in colon cancer patients and $67.90 \%$ in rectum cancer patients, similar to the findings of Moghimi-Dehkordi and Safaee [16] and Fang et al. [17]. Certain characteristics related to disease progression were strongly associated with the 5 -year risk of death from CRC: age $\geq 65$ years, high grade of pathological differentiation, perineural nerve invasion, distant metastasis, obstruction and multiple regional lymph node metastases; each independently increased the risk of death by factors of 1.38 to almost 3. In the present study, we found that BMI, smoking, drinking, and chewing betel nut were not significant predictors of CRC, colon cancer, or rectum cancer survival. This may be explained by different lifestyle practices and changing dietary patterns. However, our study did not include information on diet and physical activity level. On the other hand, it may be related to the different proportions of colon and rectum 
Table I. Demographic and clinical characteristics of colorectal cancer patients $(N=869)$

\begin{tabular}{|c|c|c|c|}
\hline Parameter & $\begin{array}{c}\text { Overall } \\
n(\%)\end{array}$ & $\begin{array}{l}\text { Colon } \\
n(\%)\end{array}$ & $\begin{array}{c}\text { Rectum } \\
n(\%)\end{array}$ \\
\hline \multicolumn{4}{|l|}{ Gender: } \\
\hline Male & $454(52.40)$ & $271(48.92)$ & $183(58.10)$ \\
\hline Female & $415(47.76)$ & $283(51.08)$ & $132(41.90)$ \\
\hline \multicolumn{4}{|l|}{ Age: } \\
\hline Mean (range) [years] & $71.27 \pm 1.27(17-97)$ & $71.90 \pm 1.58(17-93)$ & $67.88 \pm 1.95(26-97)$ \\
\hline$<65$ years old & $435(50.06)$ & $261(47.11)$ & $174(55.24)$ \\
\hline$\geq 65$ years old & $434(49.94)$ & $293(52.89)$ & $141(44.76)$ \\
\hline \multicolumn{4}{|l|}{ BMI: } \\
\hline $18.5-24 \mathrm{~kg} / \mathrm{m}^{2}$ & $374(43.04)$ & $301(54.33)$ & $151(47.94)$ \\
\hline$\geq 24 \mathrm{~kg} / \mathrm{m}^{2}$ & $386(44.42)$ & $192(34.66)$ & $116(36.83)$ \\
\hline Unknown & $109(12.54)$ & $61(11.01)$ & $48(15.23)$ \\
\hline \multicolumn{4}{|l|}{ Smoking: } \\
\hline No & $602(69.28)$ & $407(73.47)$ & $(61.90)$ \\
\hline Yes & $160(18.41)$ & $87(15.70)$ & $73(23.17)$ \\
\hline Unknown & $107(12.31)$ & $90(10.83)$ & $46(14.93)$ \\
\hline \multicolumn{4}{|l|}{ Drinking: } \\
\hline No & 642 (73.88) & 421 (75.99) & $221(70.16)$ \\
\hline Yes & $122(14.04)$ & $74(13.36)$ & $48(15.24)$ \\
\hline Unknown & $105(12.08)$ & $59(10.65)$ & $46(14.60)$ \\
\hline \multicolumn{4}{|l|}{ Chewing betel nut: } \\
\hline No & $733(84.35)$ & $479(86.46)$ & $254(80.63)$ \\
\hline Yes & $30(3.45)$ & $15(2.71)$ & $15(4.76)$ \\
\hline Unknown & $106(12.20)$ & $60(10.83)$ & $46(14.61)$ \\
\hline \multicolumn{4}{|l|}{ Pathological tumor status: } \\
\hline $\mathrm{T} 1 / \mathrm{T} 2$ & $231(26.58)$ & $134(24.19)$ & 97 (30.79) \\
\hline $\mathrm{T} 3$ & $468(53.86)$ & $285(51.44)$ & $183(58.11)$ \\
\hline T4 & $170(19.56)$ & $135(24.37)$ & $35(11.11)$ \\
\hline \multicolumn{4}{|l|}{ Cancer stage: } \\
\hline 1 & $190(21.86)$ & $113(20.40)$ & $77(24.44)$ \\
\hline II & $238(27.39)$ & $167(30.14)$ & $71(22.54)$ \\
\hline$\underline{\text { III }}$ & $303(34.87)$ & $180(32.49)$ & $123(39.05)$ \\
\hline IV & $138(15.88)$ & $94(16.97)$ & $44(13.97)$ \\
\hline \multicolumn{4}{|l|}{ Histopathology type: } \\
\hline Adenocarcinoma & $797(91.71)$ & $493(89.71)$ & $300(95.24)$ \\
\hline Mucinous carcinoma & $64(7.36)$ & $53(9.57)$ & $11(3.49)$ \\
\hline Signet ring-cell carcinoma & $8(0.92)$ & $4(0.72)$ & $4(1.27)$ \\
\hline \multicolumn{4}{|l|}{ Distant metastasis: } \\
\hline No & $747(85.96)$ & $470(84.84)$ & $277(87.94)$ \\
\hline Yes & $122(14.04)$ & $84(15.16)$ & $78(12.06)$ \\
\hline \multicolumn{4}{|c|}{ Number of regional lymph nodes involved: } \\
\hline No & $476(54.78)$ & $316(57.04)$ & $160(50.79)$ \\
\hline Yes & $393(45.22)$ & $238(42.96)$ & $155(49.21)$ \\
\hline \multicolumn{4}{|l|}{ No. of lymph nodes examined: } \\
\hline$<12$ & $222(25.55)$ & $132(23.83)$ & $90(28.57)$ \\
\hline$\geq 12$ & $647(74.45)$ & $422(76.17)$ & $225(71.48)$ \\
\hline
\end{tabular}


Table I. Cont.

\begin{tabular}{|c|c|c|c|}
\hline Parameter & $\begin{array}{c}\text { Overall } \\
n(\%)\end{array}$ & $\begin{array}{l}\text { Colon } \\
n(\%)\end{array}$ & $\begin{array}{l}\text { Rectum } \\
n(\%)\end{array}$ \\
\hline \multicolumn{4}{|c|}{ Pathological differentiation: } \\
\hline Low grade & $773(89.0)$ & $478(86.28)$ & $295(93.65)$ \\
\hline High grade & $96(11.0)$ & $76(13.72)$ & $20(6.35)$ \\
\hline \multicolumn{4}{|l|}{ Tumor size: } \\
\hline$<50 \mathrm{~mm}$ & $528(60.41)$ & $341(61.55)$ & $187(59.37)$ \\
\hline$\geq 50 \mathrm{~mm}$ & $281(32.15)$ & $185(33.39)$ & $96(30.48)$ \\
\hline Unknown & $60(7.44)$ & $28(5.06)$ & $32(10.15)$ \\
\hline \multicolumn{4}{|l|}{ CEA: } \\
\hline$<5.0 \mathrm{ng} / \mathrm{ml}$ & $34(3.91)$ & $6(1.08)$ & $5(1.59)$ \\
\hline$\geq 5.0 \mathrm{ng} / \mathrm{ml}$ & $692(79.63)$ & $448(79.42)$ & $275(87.30)$ \\
\hline Unknown & $143(6.46)$ & $108(19.50)$ & $35(11.11)$ \\
\hline \multicolumn{4}{|l|}{ CRM: } \\
\hline Negative & $826(94.55)$ & $520(93.87)$ & $296(93.97)$ \\
\hline Positive & $47(5.45)$ & $30(5.41)$ & $17(5.40)$ \\
\hline Unknown & 6 & $4(0.72)$ & $2(0.63$ \\
\hline \multicolumn{4}{|c|}{ KRAS mutation: } \\
\hline No & $43(4.95)$ & $29(5.2)$ & $14(4.4)$ \\
\hline Yes & $25(2.88)$ & $20(3.6)$ & 51.6) \\
\hline Unknown & $801(92.17)$ & $505(91.2)$ & $296(94.6)$ \\
\hline \multicolumn{4}{|c|}{ Perineural invasion: } \\
\hline No & $496(54.68)$ & $287(51.80)$ & $163(51.75)$ \\
\hline Yes & $373(45.32)$ & $267(48.20)$ & $152(48.25)$ \\
\hline \multicolumn{4}{|l|}{ Obstruction: } \\
\hline No & $512(58.92)$ & $312(56.32)$ & $200(63.49)$ \\
\hline Yes & $357(41.08)$ & $242(43.63)$ & $115(36.51)$ \\
\hline \multicolumn{4}{|l|}{ Perforation: } \\
\hline No & $853(98.16)$ & $543(98.01)$ & $310(98.41)$ \\
\hline Yes & $16(1.84)$ & $11(1.79)$ & $5(1.51)$ \\
\hline
\end{tabular}

Table II. One, three and five-year relative survival and mean survival for colorectal cancer patients

\begin{tabular}{|c|c|c|c|}
\hline Survival & Relative survival rate (\%) & Mean survival [months] & $95 \% \mathrm{Cl}$ \\
\hline Colorectal cancer $(n=869)$ : & & $71.27 \pm 1.27$ & $68.79-73.75$ \\
\hline 1-year & 95.28 & & \\
\hline 3-year & 79.45 & & \\
\hline 5-year & 68.66 & & \\
\hline Colon cancer $(n=554)$ : & & $71.90 \pm 1.58$ & $68.80-75.00$ \\
\hline 1-year & 95.56 & & \\
\hline 3-year & 80.56 & & \\
\hline 5-year & 69.11 & & \\
\hline Rectum cancer $(n=315)$ : & & $67.88 \pm 1.95$ & $64.55-71.71$ \\
\hline 1-year & 94.79 & & \\
\hline 3-year & 77.56 & & \\
\hline 5-year & 67.90 & & \\
\hline
\end{tabular}


A

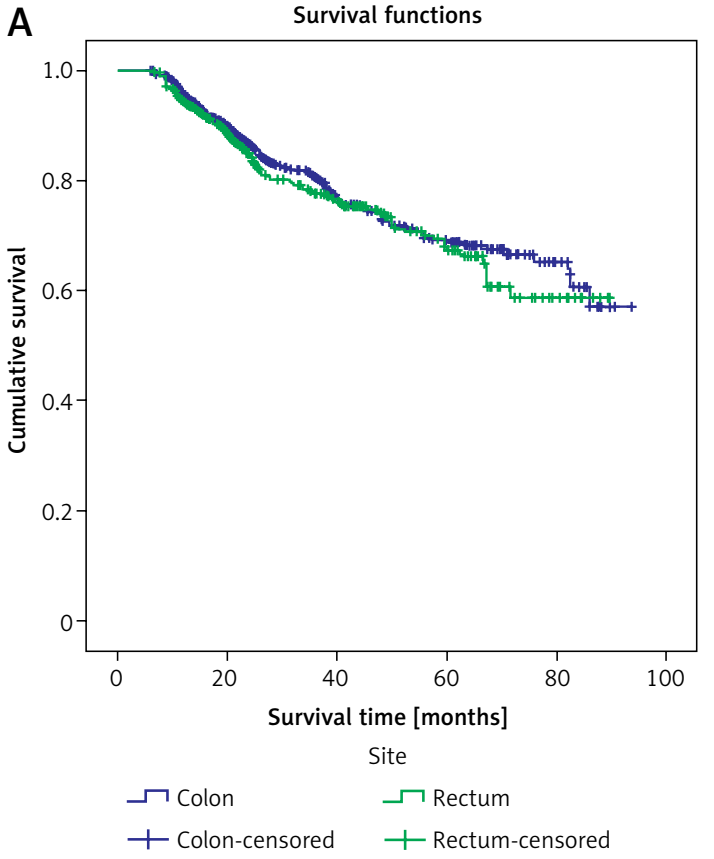

B

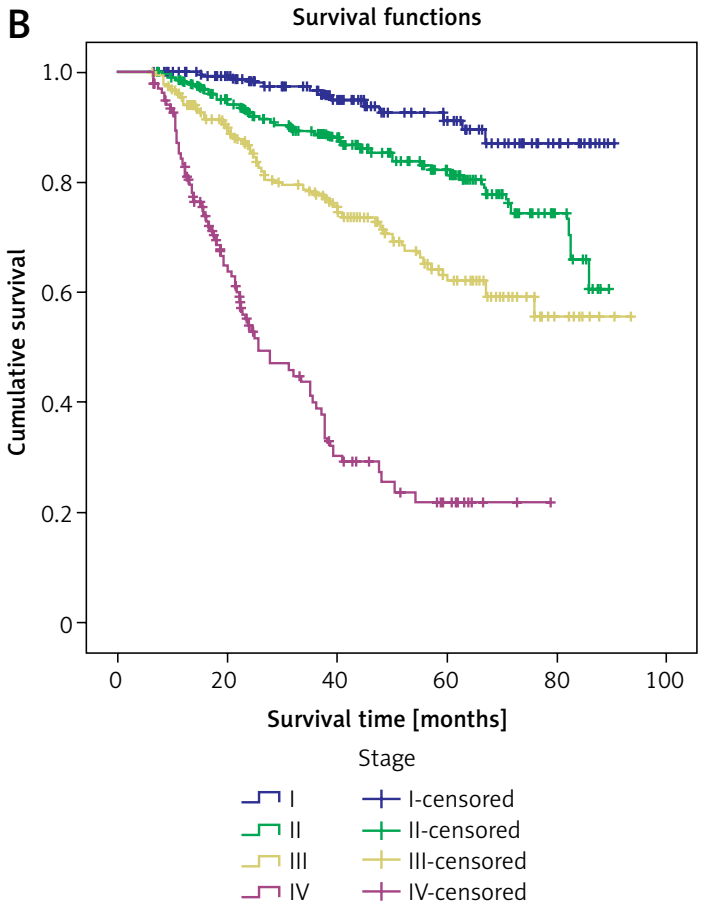

Figure 1. A - Kaplan-Meier curves of patients with colon and rectum cancer. B - Kaplan-Meier curves of colorectal cancer by stage of disease
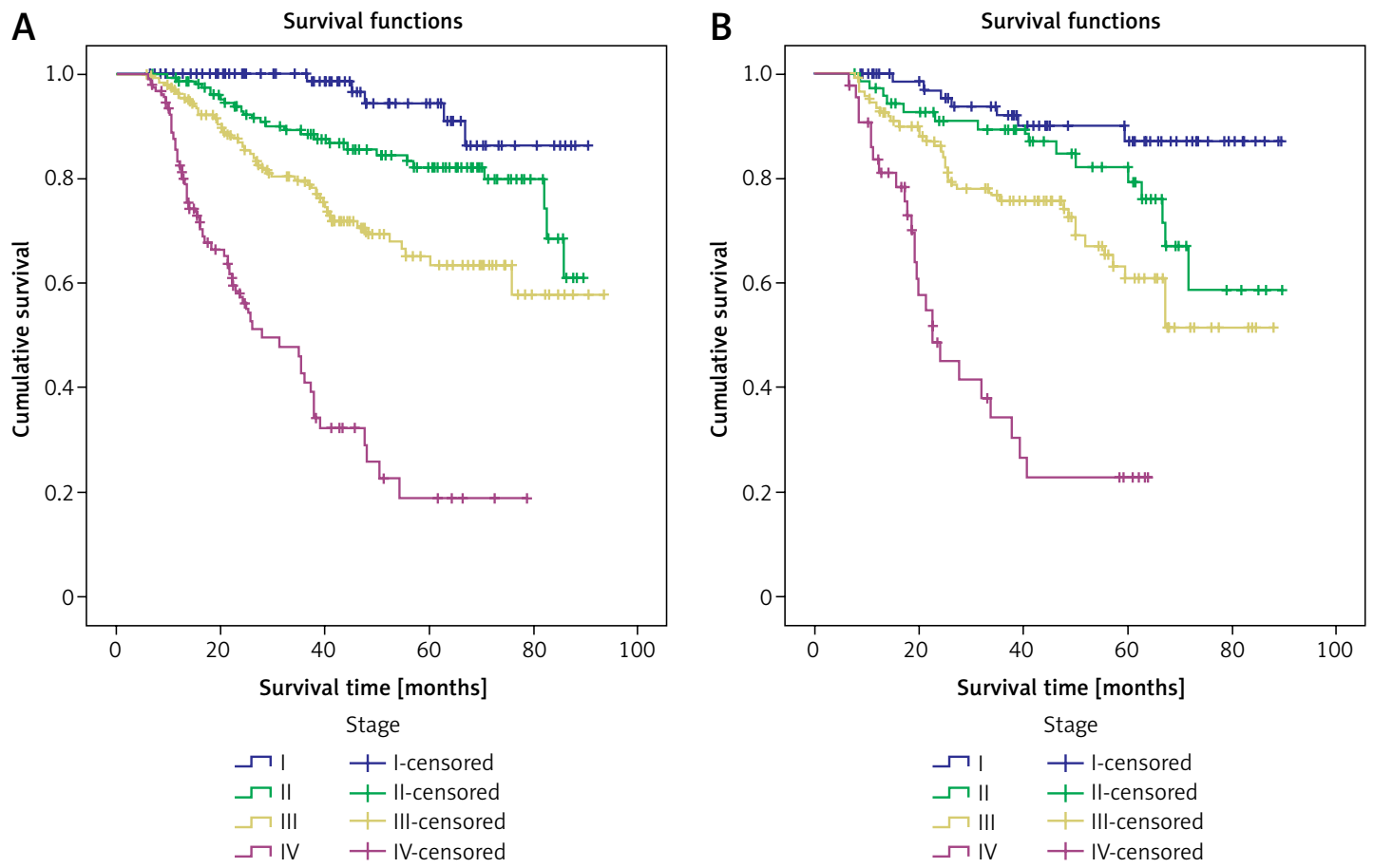

Figure 2. A - Kaplan-Meier curves of colon cancer by stage of disease. B - Kaplan-Meier curves of rectum cancer by stage of disease

cancer patients in the different studies. Further research should be undertaken to collect these data and assess these factors.

Colorectal cancer, colon cancer, and rectum cancer were more frequently found in men than women. In the present study, more than half of the subjects were male, but gender was not found to be a significant factor related to overall survival analyses. Similarly, Fang et al. [9] and Çetin et al. [18] established in previous studies that gender was not a significant prognostic factor. Younger age is a positive prognostic factor. In the present study, after adjustment for the relevant control variables, we found that age $\geq 65$ years old was 
Table III. Cox regression univariate analysis

\begin{tabular}{|c|c|c|c|c|c|c|}
\hline \multirow[t]{2}{*}{ Parameter } & \multicolumn{2}{|c|}{$\begin{array}{l}\text { Colorectal cancer } \\
\text { Univariate analysis }\end{array}$} & \multicolumn{2}{|c|}{$\begin{array}{c}\text { Colon cancer } \\
\text { Univariate analysis }\end{array}$} & \multicolumn{2}{|c|}{$\begin{array}{c}\text { Rectum cancer } \\
\text { Univariate analysis }\end{array}$} \\
\hline & HR & $95 \% \mathrm{Cl}$ & HR & $95 \% \mathrm{Cl}$ & HR & $95 \% \mathrm{Cl}$ \\
\hline \multicolumn{7}{|l|}{ Age: } \\
\hline \multicolumn{7}{|l|}{$<65$ years old } \\
\hline$\geq 65$ years old & 1.87 & $1.42-2.47$ & 1.98 & $1.38-2.85$ & 1.77 & $1.15-2.72$ \\
\hline \multicolumn{7}{|l|}{ Tumor status: } \\
\hline \multicolumn{7}{|l|}{$\mathrm{T} 1 / \mathrm{T} 2$} \\
\hline T3 & 8.74 & $5.23-14.60$ & 9.94 & $4.75-20.79$ & 3.44 & $1.75-6.76$ \\
\hline $\mathrm{T} 4$ & 3.54 & $2.16-5.82$ & 3.9 & $1.88-8.16$ & 11.35 & $5.23-24.62$ \\
\hline \multicolumn{7}{|c|}{ Regional lymph node metastasis: } \\
\hline \multicolumn{7}{|l|}{ No } \\
\hline Yes & 3.05 & $2.29-4.05$ & 2.39 & $1.95-2.93$ & 1.83 & $1.43-2.36$ \\
\hline \multicolumn{7}{|l|}{ Distant organ metastasis: } \\
\hline \multicolumn{7}{|l|}{ No } \\
\hline Yes & 5.57 & $4.16-7.45$ & 6.24 & $4.34-8.98$ & 4.75 & $2.88-7.81 w$ \\
\hline \multicolumn{7}{|l|}{ Cancer stage: } \\
\hline \multicolumn{7}{|l|}{1} \\
\hline II & 2.55 & $1.34-4.86$ & 3.21 & $1.23-8.36$ & 2.32 & $0.95-5.70$ \\
\hline III & 5.01 & $2.73-9.18$ & 6.68 & $2.66-16.80$ & 3.94 & $1.75-8.88$ \\
\hline IV & 18.96 & $10.28-34.96$ & 26.27 & $10.45-66.02$ & 14.41 & $6.17-33.67$ \\
\hline \multicolumn{7}{|l|}{ Histology type: } \\
\hline \multicolumn{7}{|l|}{ Adenocarcinoma } \\
\hline Mucinous carcinoma & 1.77 & $1.16-2.71$ & 8.13 & $2.99-22.10$ & 2.12 & $0.923-4.87$ \\
\hline Signet ring-cell carcinoma & 2.80 & $1.04-7.55$ & 1.75 & $1.07-2.89$ & 0.000 & $0.000-3.71$ \\
\hline \multicolumn{7}{|l|}{ Pathological differentiation: } \\
\hline \multicolumn{7}{|l|}{ Low grade } \\
\hline High grade & 2.20 & $1.56-3.10$ & 2.22 & $1.48-3.34$ & 2.44 & $1.26-4.72$ \\
\hline \multicolumn{7}{|l|}{ Tumor size: } \\
\hline \multicolumn{7}{|l|}{$<50 \mathrm{~mm}$} \\
\hline$\geq 50 \mathrm{~mm}$ & 1.53 & $1.15-2.03$ & & & 2.03 & $1.29-3.18$ \\
\hline \multicolumn{7}{|l|}{ KRAS mutation: } \\
\hline \multicolumn{7}{|l|}{ No } \\
\hline Yes & 3.90 & $1.45-10.51$ & 0.27 & $0.09-0.83$ & 0.28 & $0.03-2.35$ \\
\hline \multicolumn{7}{|l|}{ CRM: } \\
\hline Negative & & & & & & \\
\hline Positive & 2.18 & $1.43-3.31$ & 2.12 & $1.23-3.63$ & 2.42 & $1.25-4.71$ \\
\hline Perineural invasion: & & & & & & \\
\hline No & & & & & & \\
\hline Yes & 4.43 & $3.22-6.10$ & 4.46 & $2.95-6.73$ & 4.31 & $2.59-7.17$ \\
\hline Obstruction: & & & & & & \\
\hline No & & & & & & \\
\hline Yes & 1.87 & $1.43-2.44$ & 1.93 & $1.37-2.73$ & 1.79 & $1.17-2.75$ \\
\hline Perforation: & & & & & & \\
\hline No & & & & & & \\
\hline Yes & 2.28 & $1.07-4.84$ & & & & \\
\hline
\end{tabular}


Table IV. Forward stepwise Cox regression analysis

\begin{tabular}{|c|c|c|c|c|c|c|}
\hline \multirow[t]{2}{*}{ Parameter } & \multicolumn{2}{|c|}{$\begin{array}{l}\text { Colorectal cancer } \\
\text { Univariate analysis }\end{array}$} & \multicolumn{2}{|c|}{$\begin{array}{c}\text { Colon cancer } \\
\text { Univariate analysis }\end{array}$} & \multicolumn{2}{|c|}{$\begin{array}{c}\text { Rectum cancer } \\
\text { Univariate analysis }\end{array}$} \\
\hline & HR & $95 \% \mathrm{Cl}$ & HR & $95 \% \mathrm{Cl}$ & HR & 95\% Cl \\
\hline Age: & 2.36 & $1.76-3.17$ & 2.87 & $1.91-4.30$ & 2.39 & $1.49-3.83$ \\
\hline \multicolumn{7}{|l|}{$<65$ years old } \\
\hline \multicolumn{7}{|l|}{$\geq 65$ years old } \\
\hline Pathological differentiation: & 1.84 & $1.27-2.66$ & 1.73 & $1.09-2.75$ & 2.59 & $1.27-5.29$ \\
\hline \multicolumn{7}{|l|}{ Low grade } \\
\hline \multicolumn{7}{|l|}{ High grade } \\
\hline Perineural invasion: & 2.90 & $2.03-4.14$ & 2.60 & $1.65-4.10$ & 4.16 & $2.29-7.57$ \\
\hline \multicolumn{7}{|l|}{ No } \\
\hline \multicolumn{7}{|l|}{ Yes } \\
\hline Distant metastasis: & 2.78 & $2.00-3.87$ & 3.21 & $2.09-4.92$ & 2.48 & $1.39-4.42$ \\
\hline \multicolumn{7}{|l|}{ No } \\
\hline \multicolumn{7}{|l|}{ Yes } \\
\hline Obstruction: & 1.38 & $1.04-1.84$ & & & & \\
\hline \multicolumn{7}{|l|}{ No } \\
\hline \multicolumn{7}{|l|}{ Yes } \\
\hline Regional lymph node metastasis: & 1.81 & $1.28-2.57$ & 1.86 & $1.44-2.39$ & & \\
\hline \multicolumn{7}{|l|}{ No } \\
\hline \multicolumn{7}{|l|}{ Yes } \\
\hline Tumor size: & & & & & 1.65 & $1.03-2.63$ \\
\hline \multicolumn{7}{|l|}{$<50 \mathrm{~mm}$} \\
\hline$\geq 50 \mathrm{~mm}$ & & & & & & \\
\hline
\end{tabular}

associated with an increased risk of death of 2.36 (95\% Cl: 1.76-3.17). Similarly, Fang et al. [9], Wang et al. [13], and Kornprat et al. [19] reported that patient age at diagnosis appears to be an important prognostic factor for all patients. Previous studies found that younger patients had a worse prognosis [20] because patients younger than 50 years did not qualify for screening and likely presented symptomatic disease and had a poorer prognosis. Therefore, reducing the age at which patients should be screened for this condition could lead to improved outcomes. Such strategies as fecal occult blood testing using immunochemical methods could easily be implemented. In the current studies, when controlling for tumor stage, patient, and treatment factors, young patients had a superior overall survival.

The overall 5-year survival rate in the present study was $68.70 \%$; this result is better than that reported by the HPA [5], Fang et al. [9] in Taiwan, and the American Cancer Society, which estimated survival rates of $63.0 \%, 55.69 \%$, and $66 \%$, respectively. In the present study, the overall stage-specific 5-year survival rate for stage I-IV was $91.20 \%$, $82.20 \%, 63.20 \%$, and $21.70 \%$, respectively. Mathur et al. [7] reported that stage I and stage II CRC have an $80-90 \%$ 5-year survival rate, whereas stage III and stage IV metastatic diseases are associated with 5 -year survival rates of $60 \%$ and $8 \%$, respec- tively. In comparison, the survival rates found in the present study were higher than those previously reported. The risk of death in stage II, III, and IV CRC compared to stage I was 2.55 (95\% Cl: 1.34-4.86, $p<0.001)$, 5.01 (95\% Cl: 2.73-9.18, $p<0.001)$, and 18.96 (95\% Cl: 10.28-34.96, $p<0.001)$, respectively. Similarly, studies by Kao et al. [21] and Tsai et al. [22] supported the conclusion that the number of regional lymph node metastases in CRC is an important factor of CRC survival. In addition to AJCC stage, it is possible that other factors influence the survival rate. Thus, previous studies estimating the survival rate investigated pathology results, such as tumor site, size, grade, histology, regional lymph node metastases, perineural invasion and other variables in addition to the AJCC stage, T stage, $\mathrm{N}$ stage, and $\mathrm{M}$ stage as independent variables [20, 21, 23, 24].

In most cases, early-stage CRC does not present obvious symptoms; as such, muscle infiltration or distant metastases have occurred by the time of diagnosis. In this study, we found that tumor status, regional lymph node metastasis, and distant metastasis independently affect the survival rate of CRC patients. These results are consistent with CRC survival rate estimates reported by ZareBandamiri et al. [25], Agüero et al. [26], and Yuan et al. [27]. The present findings show that highgrade pathological differentiation was associated 
with a relative excess hazard for death of $1.84(95 \%$ Cl: $1.27-2.66, p=0.001)$. Similarly, Zare-Bandamiri et al. [25], Yuan et al. [27], and Kinoshita et al. [28] reported that grade level can independently affect the survival rate of CRC patients. This finding indicates that early CRC staging has a positive effect on survival rate. Therefore, the earlier detection of CRC should lead to substantial improvements in survival. Some researchers have suggested that CRC screenings should begin at $<50$ years of age $[9,13,23]$.

In the present study, univariate analysis revealed that histology type was an important factor. There were significant percentages of mucinous adenocarcinoma (7.36\%) and signet-ring cell carcinoma $(0.92 \%)$. These findings are similar to those of previous CRC studies $[9,23,27]$. The results showed that the risk of death in mucinous adenocarcinoma and signet-ring cell CRC with adenocarcinoma was 1.77 (95\% Cl: $1.16-2.71, p=0.008)$ and 2.80 (95\% Cl: $1.04-7.55, p=0.042$ ), respectively. These results support the findings of Fang et al. [9] and Yuan et al. [27], who found that the histology type of CRC was a risk factor for mortality. However, in the forward stepwise Cox regression analysis, histology type did not independently affect the survival rate of $C R C$ patients.

In this study, we found that perineural invasion was associated with a relative excess hazard for death of 4.43 (95\% Cl: 3.22-6.10, $p<0.001)$. Furthermore, our forward stepwise Cox regression analysis showed that perineural invasion was associated with improved predictions of CRC prognosis, which was in agreement with previous reports [9, 29-31]. After adjustment with the relevant control variables, we found that peripheral invasion remained an independent predictor of patient survival and prognosis. The importance of this factor should be considered by clinicians when assessing the prognosis of patients.

Previous studies showed that obstruction was a significant factor affecting the survival of CRC patients. In the present study, the univariate Cox regression analysis demonstrated better survival in patients without obstruction $(\mathrm{HR}=1.87,95 \% \mathrm{Cl}$ : 1.43-2.44, $p<0.001$ ). After adjustment for the relevant control variables, we found that obstruction was associated with a relative excess hazard for death of 1.38 (95\% Cl: 1.04-1.84, $p=0.026)$. These findings are similar to those of Cennamo et al. [32] and Fu et al. [33].

In conclusion, we found that perineural invasion, distant metastasis, age, pathological differentiation grade, obstruction and regional lymph node metastasis are independent predictors of the survival and prognosis of patients with CRC. Perineural invasion and distant metastasis appeared to be important prognostic factors affecting the entire patient cohort, and the earlier detection of CRC would improve patient survival.
One limitation of this study was the small sample size; in addition, the findings were generated using data from a single medical center hospital in North Taiwan. Thus, the results of some survival comparisons were not significant. These limitations should be considered when applying these results to other districts in Taiwan that may have demographic differences. Furthermore, multicenter studies should be conducted to merge patient datasets for further research in Taiwan.

\section{Acknowledgments}

We would like to acknowledge the Cancer Registry Division, Cathay General Hospital for its technical assistance during this study.

\section{Conflict of interest}

The authors declare no conflict of interest.

\section{References}

1. Bray F, Ferlay J, Soerjomataram I, Siegel RL, Torre LA, Jemal A. Global cancer statistics 2018: GLOBOCAN estimates of incidence and mortality worldwide for 36 cancers in 185 countries. CA Cancer J Clin 2018; 68: 394-424.

2. Siegel RL, Miller KD, Jemal A. Cancer statistics, 2018. CA Cancer J Clin 2018; 69: 7-34.

3. Stewart BW, Wild CP (eds.). World cancer report 2014. International Agency for Research on Cancer, World Health Organization. Revised 22 January 2016. http:// publications.iarc.fr/Non-Series-Publications/World-Cancer-Reports/World-Cancer-Report-2014.

4. Torre LA, Bray F, Siegel RL, Ferlay J, Lortet-Tieulent J, Jemal A. Global cancer statistics, 2012. CA Cancer J Clin 2015; 65: 87-108.

5. Ministry of Health and Welfare. 2018 Taiwan Health and Welfare Report. Revised 13 September 2019. http:// www.cdway.com.tw/gov/mhw2/book107/book1e/.

6. Cancer Net. Colorectal cancer-statistics. Revised 22 January 2016. http://Cancer.Net/cancer-types/colorectal-cancer/ statistics.

7. Mathur A, Ware C, Davis L, Gazdar A, Pan BS, Lutterbach B. FGFR2 is amplified in the NCI-H716 colorectal cancer cell line and is required for growth and survival. PLoS One 2014; 9: e98515.

8. Taiwan Cancer Registry. Cancer survival rates in Taiwan. Revised 22 January 2016. http://tcr.cph.ntu.edu.tw/uploadimages/Survival_98_102.pdf.

9. Fang SC, Chao TB, Tung HY, et al. Analysis of prognostic factors to predict postoperative colorectal cancer patient's survival. Med J South Taiwan 2014; 10: 75-86.

10. Beckmann KR, Bennett A, Young GP, et al. Sociodemographic disparities in survival from colorectal cancer in South Australia: a population-wide data linkage study. BMC Health Serv Res 2016; 16: 24.

11. International Agency for Research on Cancer. IARC monographs evaluate consumption of red meat and processed meat. World Health Organization. Revised 22 July 2016. http://www.iarc.fr/en/media-centre/pr/2015/ pdfs/pr240 E.pdf.

12. Perron L, Daigle JM, Vandal N, Guertin MH, Brisson J. Characteristics affecting survival after locally advanced colorectal cancer in Quebec. Curr Oncol 2015; 22: e485-92. 
13. Wang R, Wang MJ, Ping J. Clinicopathological features and survival outcomes of colorectal cancer in Young versus elderly: a population-based cohort study of SEER 9 registries data (1988-2011). Medicine (Baltimore) 2015; 94: e1402.

14. Gupta B, Johnson NW. Systematic review and metaanalysis of association of smokeless tobacco and of betel quid without tobacco with incidence of oral cancer in South Asia and the Pacific. PLoS One 2014; 9: e113385.

15. Magaji BA, Moy FM, Roslani AC, Law CW. Descriptive epidemiology of colorectal cancer in University Malaya Medical Centre, 2001 to 2010. Asian Pac J Cancer Prev 2014; 15: 6059-64.

16. Moghimi-Dehkordi B, Safaee A. An overview of colorectal cancer survival rates and prognosis in Asia. World J Gastrointest Oncol 2012; 4: 71-5.

17. Fang YJ, Wu XJ, Zhao Q, et al. Hospital-based colorectal cancer survival trend of different tumor locations from 1960 s to 2000s. PLoS One 2013; 8: e73528.

18. Çetin DA, Yildirim M, Yakan S, et al. Effects of prognostic factors on overall and disease-free survival in patients with stage I-III colorectal cancer. Arch Med Sci Civil Dis 2016; 1: e131-8.

19. Kornprat P, Pollheimer MJ, Lindtner RA, et al. Value of tumor size as a prognostic variable in colorectal cancer: a critical reappraisal. Am J Clin Oncol 2011; 34: 43-9.

20. Plummer JM, Leake PA, Ferron-Boothe D, Roberts PO, Mitchell DI, McFarlane ME. Colorectal cancer survival in Jamaica. Ann Med Surg 2016; 6: 26-9.

21. Kao LC, Yang PF, Ma CJ, et al. The impact of metastatic ratio to retrieved regional lymph nodes on overall survival in patients with stage III. J Soc Colon Rectal Surg 2013; 24: 37-43.

22. Tsai TC, Lin WL, Chang SC, et al. The survival of stage II colorectal cancer patients is significantly affected by the numbers of lymph node retrieval. Med I South Taiwan 2014; 10: 67-74.

23. Chou CL, Weng SF, Cheng LC, et al. National data on colorectal cancer trends: a population-based study in Taiwan. J Soc Colon Rectal Surg 2013; 24: 1-8.

24. Hsu YJ, Tsai WS, Hsieh PS, et al. Worse survival in rectal cancer patients with preoperative radiotherapy compared to without radiotherapy in same postoperative pathologic pN1 classification. J Soc Colon Rectal Surg 2016; 27: 7-14.

25. Zare-Bandamiri M, Khanjani N, Jahani Y, Mohammadianpanah M. Factors affecting survival in patients with colorectal cancer in Shiraz, Iran. Asian Pac J Cancer Prev 2016; 17: 159-63.

26. Agüero F, Murta-Nascimento C, Gallén M, et al. Colorectal cancer survival: results from a hospital-based cancer registry. Rev Esp Enferm Dig 2012; 104: 572-7.

27. Yuan Y, Li MD, Hu HG, et al. Prognostic and survival analysis of 837 Chinese colorectal cancer patients. World J Gastroenterol 2013; 19: 2650-9.

28. Kinoshita O, Kishimoto M, Murayama Y, et al. Poorly differentiated clusters with larger extents have a greater impact on survival: a semi-quantitative pathological evaluation for 239 patients with non-mucinous pT2-3 colorectal carcinoma. World J Surg Oncol 2015; 13: 140.

29. Hiranyakas A, da Silva G, Wexner SD, Ho YH, Allende D, Berho $M$. Factors influencing circumferential resection margin in rectal cancer. Colorectal Dis 2013; 15: 298-303.

30. Huh JW, Kim YJ, Kim HR. Ratio of metastatic to resected lymph nodes as a prognostic factor in node-positive colorectal cancer. Ann Surg Oncol 2010; 17: 2640-6.
31. Liebig C, Ayala G, Wilks J, et al. Perineural invasion is an independent predictor of outcome in colorectal cancer. J Clin Oncol 2009; 27: 5131-7.

32. Cennamo V, Luigiano C, Coccolini F, et al. Meta-analysis of randomized trials comparing endoscopic stenting and surgical decompression for colorectal cancer obstruction. Int J Colorectal Dis 2013; 28: 855-63.

33. Fu CY, Jao SW, Wu CC, et al. Comparisons of characteristics and outcome of colorectal cancer in different age categories: a retrospective analysis of a single institution in Taiwan. J Soc Colon Rectal Surg 2011; 22: 57-64. 